\title{
Thermo-Mechanical Damage Modeling of Polymer Matrix Composite Structures in Fire
}

\author{
CHANGSONG LUO, and JIM LUA \\ Global Engineering and Materials, Inc. \\ One Airport Place, Suite One \\ Princeton, NJ 08540 USA
}

\begin{abstract}
The overall objective of this research is to develop a modeling and simulation approach to predict the thermo-mechanical damage of composite materials subjected to fire environments. A three-dimensional thermal damage model is developed for glass-reinforced polymer composite materials subject to high temperature and radiative environments. Homogenization methods are used to determine the properties of damaged material in terms of the volume fractions associated with composite fiber, resin, and char and their individual phase properties. The thermal damage model is implemented in Abaqus via an overlaid element approach and extended to a thermo-mechanical damage model. The solution of the mechanical response is determined based on the existing capabilities in Abaqus with material and geometry nonlinearities. The thermal response of the laminated composite material is studied first. Consistent agreement in temperature is obtained between the numerical predictions and experimental data. The extended thermo-mechanical damage model is then applied to the sandwich structure of composite laminates subject to radiative heating and compressive loading. The predictions of temperature field match very well with experimental data. In addition, the predicted delamination pattern and time-to-failure are in reasonable agreement with the experimental data
\end{abstract}

KEYWORDS: composites, delamination, time-to-failure.

\section{NOMENCLATURE LISTING}

$\begin{array}{llll}A & \text { pre-factor of Arrhenius law }\left(\mathrm{s}^{-1}\right) & v & \text { velocity }(\mathrm{m} / \mathrm{s}) \\ c_{p} & \text { specific heat }(\mathrm{J} / \mathrm{kg} \cdot \mathrm{K}) & \text { Greek } & \\ D & \text { strain rate }\left(\mathrm{s}^{-1}\right) ; \text { damage index }(-) & \delta & \text { virtual variable } \\ E_{i} & \text { activation energy }(\mathrm{J} / \mathrm{mol}) & \delta_{\mathrm{n}} & \text { delamination opening } \\ f & \text { body force }(\mathrm{N}) & \varepsilon & \text { strain } \\ F & \text { thermal conductivity }(\mathrm{W} / \mathrm{m} \cdot \mathrm{K}) & \varphi_{i} & \text { volume fraction of each phase } \\ G & \text { fracture energy } & \rho & \text { material density } \\ \Delta h & \text { heat of decomposition }(\mathrm{J} / \mathrm{kg}) & \mu & \text { kinematic viscosity }\left(\mathrm{m}^{2} / \mathrm{s}\right) \\ K & \text { gas permeability }\left(\mathrm{m}^{2}\right) ; \mathrm{stiffness}(\mathrm{Pa}) & \sigma & \text { stress } \\ \dot{m}^{\prime \prime \prime} & \text { mass change rate }\left(\mathrm{kg} / \mathrm{m}^{3} \cdot \mathrm{s}\right) & \text { superscripts } \\ n & \text { surface normal } & f & \text { final state } \\ p_{g} & \text { gas pressure }(\mathrm{Pa}) & \text { max } & \text { maximum value } \\ q & \text { heat flux }\left(\mathrm{kW} / \mathrm{m}^{2}\right) & \text { subscripts } \\ L & \text { spatial gradient of velocity } & e x, \text { un } & \text { exposed or unexposed surface } \\ R & \text { universal gas constant }(\mathrm{J} / \mathrm{K} \cdot \mathrm{mol}) & f, r, c & \text { fiber, resin, char } \\ t & \text { surface traction } & g & \text { gas } \\ T & \text { temperature }(\mathrm{K}) & i & \text { each constituent in composite } \\ u & \text { displacement }(\mathrm{m}) & I, I I & \text { mode } 1 \text { or mode } 2\end{array}$

\section{INTRODUCTION}

Existing models for describing the thermal response of decomposing composite materials have been proposed by Henderson et al. [1-3], Dimitrienko [4-9], Feih [10-12], Summers [13], Zhang and Scott $[14,15]$, and Luo and DesJardin [16,17]. A one-dimensional transient thermal model for a glass-phenolic system was developed by Henderson and Florio et al. [1-3]. They modeled the composite as composed of virgin and burnt (char) material. Dimitrienko has systematically developed more advanced thermo- 
mechanical models for high-temperature composites using a multi-phase representation of a decomposed composite material [4-9]. In his approach, the decomposed composite is assumed to consist of fiber, resin, char, and gas. The governing equation of thermal and mechanical equations is derived using asymptotic averaging yielding a hierarchy of linearized equations [7]. Feih et al. [10-12] developed a thermomechanical model based on Henderson's model, laminate theory and a temperature-dependent strength to estimate the time-to-failure of composite structures under compressive loading and one-sided heating. The thermal model is a 1-D equation that only considers the conductive heat transfer and mass transport of decomposed gases in the through-thickness direction. The time-to-failure is determined by comparing the average compressive strength of the laminate with the compressive force. Summers [13] studied the compression failure of polymer composite laminate, using a one-dimensional heat and mass transfer model implemented within a Matlab-based toolkit. Zhang and Scott [14,15] developed a three-dimensional thermal and mechanical model by extending Henderson's 1-D thermal model and including the viscoelastic effects of composite materials in fire and implemented it in Abaqus via its user-defined material models.

Luo and DesJardin [16,17] developed a constituent based thermal decomposition model based on a homogenized system of thermal and mechanical equations using phase-averaging concepts. The developed decomposition model incorporates the effect of gas pressurization from resin decomposition in a selfconsistent manner. The solution of the equations was obtained using a finite element method. The model was exercised for the case of a 2-D clamped beam for which a plane strain assumption is imposed. Given the thermal properties at material's constituent level (fiber, resin, char, and gas), a homogenization approximation is used to characterize the thermal decomposition and mass transfer for an arbitrary composite system. With this constituent based thermal decomposition model, the fire response can be simulated for a new material system with given constituent properties and their corresponding volume fractions without performing extensive coupon level testing.

Most of the existing thermal mechanical damage models have only addressed three failure mechanisms for decomposed composite materials. They are: 1) charring, 2) gas accumulation from resin decomposition, and 3) thermal degradation of elasticity properties. However, delamination has been observed to be an important failure mode from experimental studies of loaded composite structures in fire environments $[12,13,18]$. The delamination could occur between the plies of composite laminates [13] and/or the interface between laminate and balsa core in composite sandwich structures [12]. The main objective of this study is to implement a thermal damage model in commercial finite element analysis software, such as Abaqus, and couple it with a delamination failure model to characterize the thermal degradation induced material softening and interface debonding. In the following sections, the model formulation is presented and the implementation of both thermal and delamination failure models in Abaqus is discussed.

\section{MATHMATICAL FORMULATION}

\section{Thermal Damage Model}

In order to model the response of a composite structure in fire, the macroscopic structural response needs to be determined from microscopic changes in fiber and resin due to local heating and pyrolysis. The modeling approach pursued in this study is based on the homogenization techniques where phase-averaged equations are derived for mass and energy transport within the structure $[16,17]$. The following summarizes the main results of this development. More details can be found in Ref. [19].

The initial composite material is assumed to be composed of fiber, resin, and a small amount of gas void. Upon heating, the resin heats up and is pyrolyzed, creating additional gas and char. Thermal equilibrium is assumed among the constituents therefore the solution of only a single energy equation is required for the determination of the local temperature field. The resulting phase-averaged equations for solid phase fraction, $\varphi_{i}$, gas-phase density, $\rho_{g}$, and energy (temperature) transport are summarized below $[16,19]$ :

$$
\rho_{i} \frac{\partial \varphi_{i}}{\partial t}=\dot{m}_{i}^{\prime \prime \prime} \quad i=f, r, c
$$




$$
\begin{aligned}
& \frac{\partial \rho_{g} \varphi_{g}}{\partial t}=\nabla \cdot\left(\rho_{g} \frac{\underline{\underline{K}}}{\mu_{g}} \cdot \nabla\left(\rho_{g} R_{g} T\right)\right)+\dot{m}_{g}^{\prime \prime \prime} \\
& \left(\rho c_{p}-\rho_{g} \varphi_{g} R_{g}\right) \frac{\partial T}{\partial t}=\left(\rho_{g} c_{p g}+\rho_{g} \varphi_{g} R_{g}\right)\left[\frac{\underline{\underline{K}}}{\mu_{g}} \cdot \nabla\left(\rho_{g} R_{g} T\right)\right] \cdot \nabla T \\
& +\nabla \cdot(\underline{\underline{k}} \cdot \nabla T)-\dot{m}_{g}^{\prime \prime \prime}\left(\Delta h-R_{g} T\right)
\end{aligned}
$$

The first terms on the right hand side of Eqs. 2 and 3 account for the transport of gases assuming a Darcy flow, requiring specification of the permeability tensor, $\underline{\underline{K}}$. The source/sink terms for the solid phase $\left(\dot{m}_{i}^{\prime \prime \prime}\right)$ and the gas phase $\left(\dot{m}_{g}^{\prime \prime \prime}\right)$ account for change in mass from pyrolysis. The decomposition of the glass/vinyl ester is modeled using an Arrhenius law for pyrolysis [14]. Once the volume fractions of the solid phase are determined then the gas volume fraction, $\varphi_{g}$, used in Eqs. 2 and 3 can be determined using: $\varphi_{g}=1-\varphi_{f}-\varphi_{r}-\varphi_{c}$.

\section{Cohesive Model}

Delamination has been observed as a mode of failure in experimental studies of composite structures in fire environments $[12,13,18]$. The delamination could occur between the plies of the composite laminate or at the interface between laminate and balsa core in composite sandwich structure $[12,13]$, respectively. This mode of failure can be modeled in Abaqus [20,21] using cohesive elements, or equivalently surface-based cohesive behavior, with a traction-separation description.

The cohesive model using a traction separation description assumes a linear elastic behavior followed by the damage initiation and evolution. The elastic behavior is written in terms of an elastic constitutive matrix that relates the nominal stresses to the nominal strains across the interface. The nominal stresses are the force components divided by the original area at each integration point, while the nominal strains are the separations divided by the original thickness at each integration point. The default value of the original constitutive thickness is 1.0 if traction-separation response is specified, which ensures that the nominal strain is equal to the separation, i.e., relative displacements of the top and bottom faces. The constitutive thickness used for traction-separation response is typically different from the geometric thickness, which is typically close or equal to zero [22].

The nominal traction stress, $\{t\}$, consists of three components: $t_{n}, t_{s}$, and $t_{t}$ (normal and shear tractions). The corresponding separations are $\delta_{n}, \delta_{s}$, and $\delta_{t}$. The nominal strains can be defined as

$$
\varepsilon_{n}=\frac{\delta_{n}}{T_{0}}, \varepsilon_{s}=\frac{\delta_{s}}{T_{0}}, \varepsilon_{t}=\frac{\delta_{t}}{T_{0}}
$$

where $T_{0}$ is the original constitutive (not geometric) thickness of the cohesive layer.

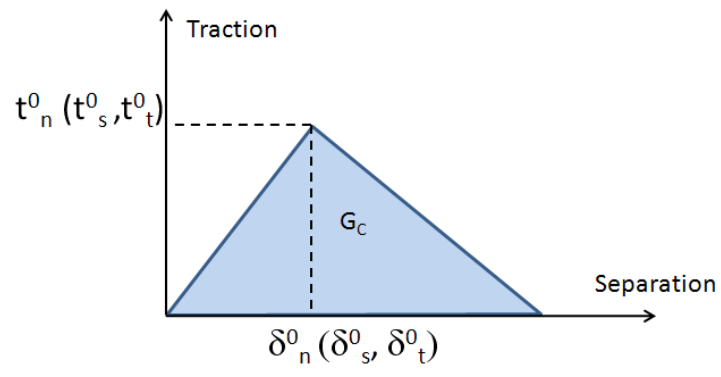

Fig. 1. Typical traction-separation response of a cohesive element. 
Figure 1 presents a typical traction-separation response of a cohesive layer. The linear elastic behavior of the initial response, before damage initiation, can be written as

$$
\{t\}=\left\{\begin{array}{l}
t_{n} \\
t_{s} \\
t_{t}
\end{array}\right\}=\left[\begin{array}{lll}
K_{n n} & K_{n s} & K_{n t} \\
K_{s n} & K_{s s} & K_{s t} \\
K_{t n} & K_{t s} & K_{t t}
\end{array}\right]\left\{\begin{array}{l}
\varepsilon_{n} \\
\varepsilon_{s} \\
\varepsilon_{t}
\end{array}\right\}=K\{\varepsilon\}
$$

Once a damage initiation criterion is reached, material damage occurs depending on the damage evolution law. Generally, damage initiation refers to the beginning of degradation of the response of a material point. For cohesive model, it indicates the start of the delamination damage. The process of damage begins when the stresses or strains satisfy certain damage initiation criteria that are specified. Abaqus provides several different criteria, which can be chosen by the users, such as maximum nominal stress or strain criterion, and quadratic nominal stress or strain criterion. In this study, the quadratic nominal stress criterion is used [22]:

$$
\left\{\frac{\left\langle t_{n}\right\rangle}{t_{n}^{0}}\right\}^{2}+\left\{\frac{t_{s}}{t_{s}^{0}}\right\}^{2}+\left\{\frac{t_{y}}{t_{t}^{0}}\right\}^{2}=1
$$

where \langle\rangle represents that compressive (negative) normal stress does not initiate any delamination damage. Damage is assumed to initiate when the above quadratic interaction criterion is satisfied. The damage evolution law is used to describe the rate at which the material stiffness is degraded once the corresponding initiation criterion is met. Abaqus provides a few different damage evolution laws, which can be found in section 28.5.6 of its Users Manual [22]. Damage evolution can be defined based on the energy that is dissipated as a result of the damage, which is also known as the fracture energy. The fracture energy is equal to the area under the traction-separation curve. When the material is completely damaged or the two surfaces are totally delaminated, the area under the linear (in this study) or the exponential damaged response is equal to the critical fracture energy, $G_{C}$ (the shaded area as shown in Fig. 2). A power law criterion states that failure under mixed-mode conditions is governed by a power law interaction of the energies required to cause failure in the individual (normal and two shear) modes [22]. The second order power law is assumed for the damage evolution in this study

$$
\left\{\frac{G_{n}}{G_{n C}}\right\}^{2}+\left\{\frac{G_{s}}{G_{s C}}\right\}^{2}+\left\{\frac{G_{t}}{G_{t C}}\right\}^{2}=1
$$

where $G_{n C}, G_{s C}, G_{t C}$ are the energies required to cause failure in the normal and two shear directions. These fracture energies can be specified as material properties.

A damage index, $D$, represents the overall damage of delamination and captures the combined effects of delamination damage in both normal and shear directions. The damage index $D$ monotonically increases from 0 to 1 upon further loading after the initiation of damage. For a linear softening behavior, the mix mode damage index can be written as

$$
D=\frac{\delta^{f}\left(\delta^{\max }-\delta^{0}\right)}{\delta^{\max }\left(\delta^{f}-\delta^{0}\right)}
$$

where $\delta^{\max }$ is the maximum effective displacement during the loading history, and $\delta^{f}$ the effective displacement at final complete failure [22]. When $\delta^{\max }$ is equal to $\delta^{0}$, Eq. 10 gives $D=0$, which 
represents when the delamination damage just initiates and no damage is caused. If $\delta^{\max }$ reaches $\delta^{f}$, the damage index $D$ equals 1 and the two surfaces are totally delaminated.

\section{SOLUTION APPROACH}

\section{Thermal Response in Abaqus}

In Abaqus, a user subroutine, UMATHT, can be used to define the thermal constitutive behavior of the material as well as internal heat generation during heat transfer processes. It can be used for solving the temperature equation represented by Eq. 3, as well the gas transport equation, Eq. 2. However, there is no such type of element that has both temperature and gas pressure degrees of freedom for heat transfer or thermal-mechanical analyses. Only one user-defined thermal material behavior can be used for each material point.

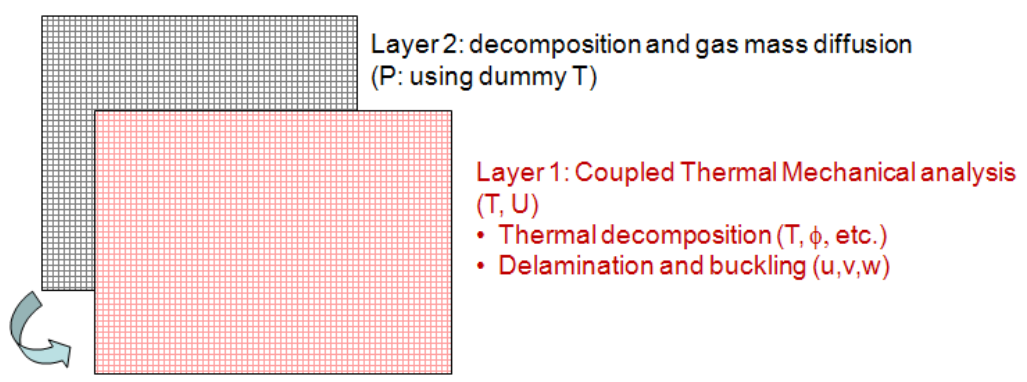

Fig. 2. Typical traction-separation response of a cohesive element.

In order to implement the thermal damage model in Abaqus, an overlaid element approach, shown in Fig. 2, is developed and implemented in Abaqus/Standard [23,24]. The two overlaid layers of elements are actually on top of each other, and plotted offset for illustration purpose. These elements have their displacement degrees of freedom fixed to each other at the nodes, which can reduce the unnecessary computational cost. The solution procedure employs one UMAT (if needed for mechanical field) and one UMATHT(1) applied to the first layer to define the constitutive, decomposition, and heat transfer equations. Another UMATHT(2) is applied to the second layer to solve the gas transport equation. Since both UMAT and UMATHT(1) are used for the first layer of elements, the common variables can be shared via the state variables associated with material points. These state variables include temperature, remaining solid mass, etc. To use these state variables as the input for the second layer of elements in UMATHT(2), common blocks are also used for transferring the data between these two layers. The pressure calculated from UMATHT(2) can also be used in UMAT and UMATHT(1) associated with the first layer of elements during the time marching scheme. In each time increment, multiple iterations are used to achieve equilibrium for the global system. Therefore, the two layers of elements are equivalent to one layer of elements that have both temperature and pressure, as well as displacement degrees of freedom.

\section{Mechanical Response in Abaqus}

The solution of the mechanical response of composite structures is based on the existing capabilities of Abaqus. It is found that the mechanical properties of composite laminates degrade as temperature increases [25]. A temperature dependent orthotropic linear elastic material model is used for the composite laminates in this study. The delamination failure can be predicted using the cohesive model with a traction-separation description, and large displacement is considered in the analysis for the geometric nonlinearity. More detailed information can be found in Abaqus manuals [20,22,26].

Nonlinear stress analysis problems can contain up to three sources of nonlinearity: geometric nonlinearity, material nonlinearity, and boundary nonlinearity. A nonlinear finite element model can involve a few or millions of variables. The problem is history-dependent, so the solution needs to be developed by a series of increments. Generally, Abaqus/Standard uses Newton's method as a numerical technique to solve the nonlinear equilibrium equations. The reason for this choice is primarily because of the convergence rate $[20,22]$. 


\section{RESULTS AND DISCUSSION}

Numerical predictions of thermal response for glass/vinyl ester laminates are presented and compared with available experimental data. Composite sandwich structures are studied using the extended thermomechanical damage model in Abaqus. Numerical results are presented and model validation is performed by comparing the displacements and time-to-failure with experimental data.

\section{Temperature Prediction of Glass/Vinyl Ester Composite Subjected to Fire}

The thermal damage model is first applied to a glass/vinyl ester composite laminate. The problem considered is sketched in Fig. 3 and consists of a composite laminate with a thickness of $9 \mathrm{~mm}$ and a width of $50 \mathrm{~mm}$ and a length of $560 \mathrm{~mm}$. The dimension is chosen to compare with the data from Feih et al. $[10,11]$. The thermal and transport properties used in the calculations are taken from Feih et al. [10,11] and are summarized in Table 1.

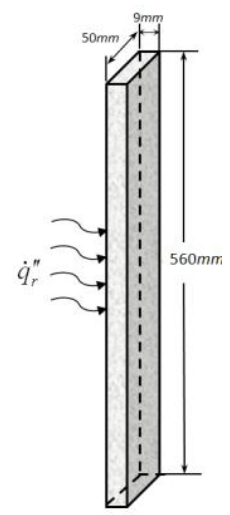

Fig. 3. A glass/vinyl ester composite laminate with local heating on the left surface.

Table 1.Material thermal and transport properties for E-glass/vinyl ester composite material [10,11].

\begin{tabular}{|l|r|}
\hline \multicolumn{1}{|c|}{ Property } & \multicolumn{1}{|c|}{ Value } \\
\hline$A_{s g}\left(\mathrm{~s}^{-1}\right)$ & $5.59 \times 10^{13}$ \\
\hline$E_{a}(\mathrm{~J} / \mathrm{kg} \cdot \mathrm{mol})$ & $212,075.0$ \\
\hline$n(-)$ & 1.0 \\
\hline$h_{d e c}(\mathrm{~J} / \mathrm{kg})$ & 378800.0 \\
\hline$\rho_{f}\left(\mathrm{~kg} / \mathrm{m}^{3}\right)$ & 2560.0 \\
\hline$\rho_{c,} \rho_{c}\left(\mathrm{~kg} / \mathrm{m}^{3}\right)$ & 1140.0 \\
\hline & $960.0(\mathrm{~T}<410 \mathrm{~K})$ \\
$c_{p}(\mathrm{~J} / \mathrm{kg} \cdot \mathrm{K})$ & $1210.0(410 \mathrm{~K}<\mathrm{T}<550 \mathrm{~K})$ \\
& $1360.0(\mathrm{~T}>550 \mathrm{~K})$ \\
\hline$k(\mathrm{~W} / \mathrm{m} \cdot \mathrm{K})$ & 0.43 \\
\hline$M W_{g}(\mathrm{~kg} / \mathrm{kmol})$ & 1.48 \\
\hline$v_{k}\left(\mathrm{~m}^{3} / \mathrm{s}\right)$ & $1.48 \times 10^{-5}+2.5 \times 10^{-5} \mathrm{~T}$ \\
\hline
\end{tabular}

A radiative heat flux is applied to the $100 \mathrm{~mm}$ center section at the left surface of the panel. A total of 40 elements are used in the through-thickness direction for the solution of the thermal response. Radiative and convective boundaries are used on exposed and unexposed surfaces for the temperature equations,

$$
\begin{aligned}
& \dot{q}_{e x}^{\prime \prime}=\dot{q}_{r}^{\prime \prime}-\varepsilon_{e x} \sigma\left(T_{s}^{4}-T_{\infty}^{4}\right)-h_{\text {conv }, e x}\left(T_{s}-T_{\infty}\right) \\
& \dot{q}_{u n}^{\prime \prime}=-\varepsilon_{e x} \sigma\left(T_{s}^{4}-T_{\infty}^{4}\right)-h_{\text {conv,un }}\left(T_{s}-T_{\infty}\right)
\end{aligned}
$$


where $\dot{q}_{r}^{\prime \prime}$ is the radiant heat flux imposed on the composite surface, the emissivity $\varepsilon_{e x}=0.9, \varepsilon_{u n}=0.6$, the Stefan-Boltzmann constant $\sigma=5.67 \times 10^{8} \mathrm{~W} / \mathrm{m}^{2} \cdot \mathrm{K}^{4}$, the convection heat flux coefficient $h_{\text {convex }}=$

$0.015 \mathrm{~kW} / \mathrm{m}^{2} \cdot \mathrm{K}, h_{\text {conv,un }}=0.005 \mathrm{~kW} / \mathrm{m}^{2} \cdot \mathrm{K}$, and the temperature in the environment $T_{\infty}=298 \mathrm{~K}$. The boundary condition on all other surfaces is thermally insulated.

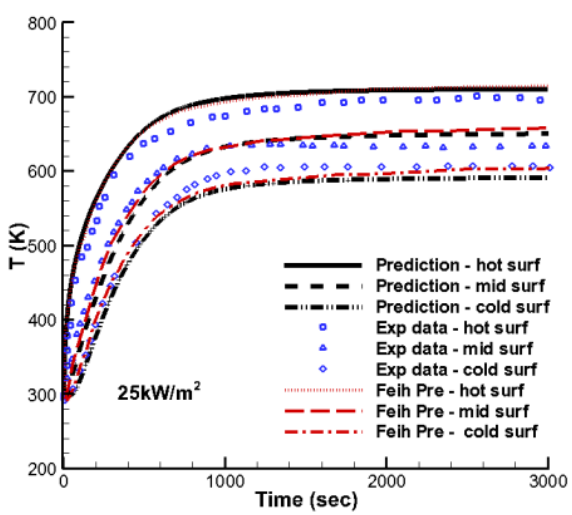

(a)

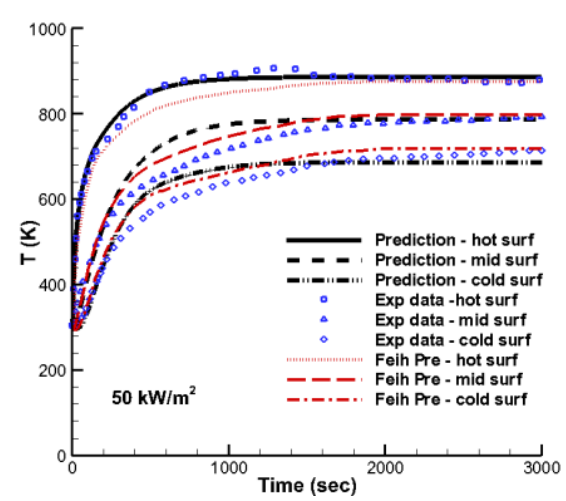

(b)

Fig. 4. Time history of temperature at hot/middle/cold surfaces of a glass/vinyl ester composite laminate with locally heating of: (a) $25 \mathrm{~kW} / \mathrm{m}^{2}$; (b) $50 \mathrm{~kW} / \mathrm{m}^{2}$ on left surface.

Figure 4 shows model predictions of temperature time history compared with experimental data and predictions from Feih et al. [10,11]. Temperatures are measured via thermocouples at the exposed surface, middle surface, and unexposed surface. As shown in Fig. 4, the temperature increases rapidly when the heat flux is applied. Because the thickness of the laminate is only $9 \mathrm{~mm}$, the middle and unexposed surfaces are heated up within $100 \mathrm{~s}$. For the $25 \mathrm{~kW} / \mathrm{m}^{2}$ case, it takes around $800 \mathrm{~s}$ for the whole sample to reach a steady state. Good agreement with the experimental data (maximum error of $9.8 \%$ ) has been achieved at the exposed, middle, and cold surfaces. With a higher heat flux, $50 \mathrm{~kW} / \mathrm{m}^{2}$, predicted temperature is higher than the measurement at the middle and unexposed surfaces in the middle stage of heating. Due to a higher temperature distribution compared to the previous case, the material decomposed. The decomposed material would have a different thermal conductivity. In the simulation, the thermal conductivity is assumed constant which might not be true in reality and be responsible for the discrepancy between prediction and experimental data. Overall the model prediction of temperature time history at different locations in the composite laminate agrees reasonably well with experimental measurements.

\section{Composite Sandwich Panel Exposed to Fire}

To validate the thermo-mechanical damage model, a sandwich composite is studied compared with the experimental data from by Feih et al. [12]. In the experimental study, both a constant compressive loading and a given heat flux are applied to measure the time-to-failure of the sandwich structure. As shown in Fig. 5, the sandwich consists of a balsa wood core and two skins of glass vinyl ester composite laminate. Both skin and core are $150 \mathrm{~mm}$ long and $80 \mathrm{~mm}$ wide. 


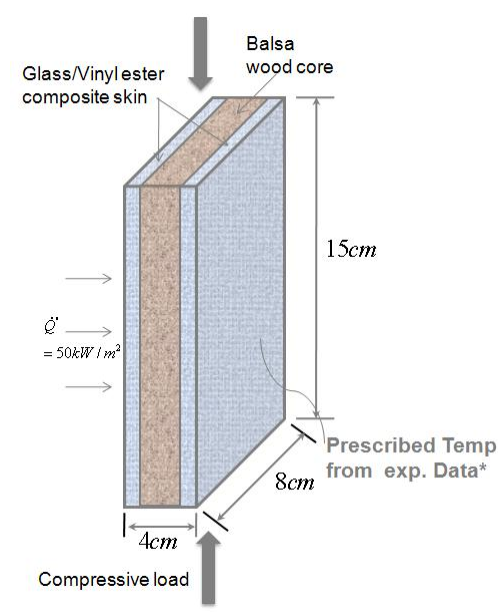

Fig. 5. A composite sandwich is under compression load with local heating on left surface.

The skin has a thickness of $5 \mathrm{~mm}$ and the core has a thickness of $30 \mathrm{~mm}$. A uniform heat flux is imposed at the center $100 \mathrm{~mm}$ (in-length) area on one side of the sandwich, and a constant compressive force is applied on the top surface. Since the clamps used to restraint the specimen on both ends were not fixed to the compression plates, the boundary condition allowed free rotation (pinned) along the width direction.

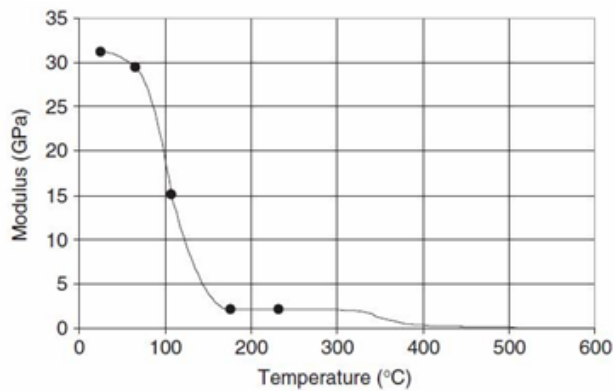

(a)

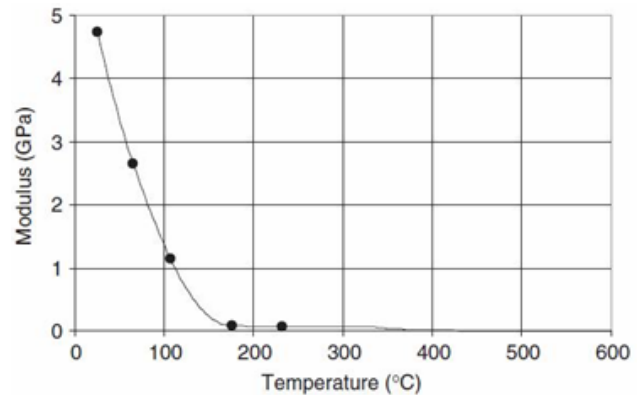

(b)

Fig. 6. Temperature dependency of: (a) longitudinal modulus; (b) shear modulus of the E-glass/vinyl ester composite [25].

Table 2. Material thermal and transport properties for balsa wood [27,28].

\begin{tabular}{|l|r|}
\hline \multicolumn{1}{|c|}{ Property } & \multicolumn{1}{c|}{ Value } \\
\hline$A_{s g}\left(\mathrm{~s}^{-1}\right)$ & $6.7 \times 10^{13}$ \\
\hline$E_{a}(\mathrm{~J} / \mathrm{kg} \cdot \mathrm{mol})$ & $116,488.0$ \\
\hline$n(-)$ & 1.0 \\
\hline$h_{\text {dec }}(\mathrm{J} / \mathrm{kg})$ & 556000.0 \\
\hline$\rho_{f}\left(\mathrm{~kg} / \mathrm{m}^{3}\right)$ & 150.0 \\
\hline$\rho_{c,} \rho_{c}\left(\mathrm{~kg} / \mathrm{m}^{3}\right)$ & 22.0 \\
\hline$c_{p}(\mathrm{~J} / \mathrm{kg} \cdot \mathrm{K})$ & $1420.0+0.68 \mathrm{~T}$ \\
\hline$c_{p, c h a r}(\mathrm{~J} / \mathrm{kg}-\mathrm{K})$ & $3195.0+1.33 \mathrm{~T}$ \\
\hline$k(\mathrm{~W} / \mathrm{m}-\mathrm{K})$ & 0.2 \\
\hline
\end{tabular}

The thermal and transport properties of the glass vinyl ester composite laminate and the balsa wood are summarized in Tables 1 and 2 [27,28], respectively. The mechanical properties of E-glass/vinyl ester laminate at room temperature are given in Table $3[29,30]$. The temperature dependency of mechanical properties of woven E-glass/vinyl ester laminate is critical to the prediction of the time-to-failure of the structure. According to the experimental studies by Kim et al. [25], the longitudinal modulus and the shear 
modulus degrade differently as temperature increases, as shown in Fig. 6. The curves are normalized to represent the temperature dependency. The coefficient of thermal expansion (CTE) of the composite in this case is also orthotropic. Both in-plane and out-of-plane CTEs are temperature dependent, and given in Table 3.

Table 3. Mechanical properties for E-glass/vinyl ester laminate [29,30].

\begin{tabular}{|l|r|}
\hline \multicolumn{1}{|c|}{ Property } & Value \\
\hline$E_{11,}, E_{22}(\mathrm{~Pa})$ & $2.68 \times 10^{10}$ \\
\hline$E_{33}(\mathrm{~Pa})$ & $1.15 \times 10^{10}$ \\
\hline$v_{12}(-)$ & 0.15 \\
\hline$v_{13,}, v_{23}(-)$ & 0.4 \\
\hline & \\
\hline$G_{12}(\mathrm{~Pa})$ & $5.04 \times 10^{9}$ \\
\hline$G_{13,}, G_{23}(\mathrm{~Pa})$ & $3.64 \times 10^{9}$ \\
\hline & $(-0.0094 \mathrm{~T}+11.024) \times 10^{-6}(\mathrm{~T}<627.5 \mathrm{~K})$ \\
$\alpha_{11}\left(\mathrm{~K}^{-1}\right)$ & $(-0.0404 \mathrm{~T}+22.013) \times 10^{-6}(627.5<\mathrm{T}<694.1 \mathrm{~K})$ \\
& $5.0 \times 10^{-6}(\mathrm{~T}>694.1 \mathrm{~K})$ \\
\hline & $34.5 \times 10^{-6}(\mathrm{~T}>374.4 \mathrm{~K})$ \\
$\alpha_{33}\left(\mathrm{~K}^{-1}\right)$ & $\{44+74 \tanh [0.015(\mathrm{~T}-110)]\} \times 10^{-6}(374.4<\mathrm{T}<627.5 \mathrm{~K})$ \\
& $(718.85-1.6952 \mathrm{~T}) \times 10^{-6}(627.5<\mathrm{T}<694.1 \mathrm{~K})$ \\
& $5.0 \times 10^{-6}(\mathrm{~T}>694.1 \mathrm{~K})$ \\
\hline
\end{tabular}

The transient thermal-mechanical (coupled temperature and displacement) analysis is conducted in Abaqus. The user subroutines (UMATHT and DFLUX etc.) provide the functionalities to define complicated materials, such as composite laminate and balsa wood with temperature dependent thermal and transport properties, and temperature dependent thermal boundary conditions. A radiation and convection mixed type of thermal boundary condition is used on the heated area. For the exposed area, there is radiant energy absorbed and heat is lost by convection. The net heat gain by the materials can be evaluated by

$\dot{q}_{n e t}^{\prime \prime}=\dot{q}_{r}^{\prime \prime}-\delta \sigma\left(T_{s}^{4}-T_{\infty}^{4}\right)-h_{\text {conv }}\left(T_{s}-T_{\infty}\right)$

where $\varepsilon$ and $\alpha$ the emissivity and absorptivity are assumed to be the same, and the surrounding temperature $T_{\infty}$ is $300 \mathrm{~K}$. The initial temperature is assumed uniform through the thickness, $T_{i n i}=300 \mathrm{~K}$. The boundary condition on the back surface is not well defined since a thick insulation plate was attached on the back cold surface; therefore a curve fitted temperature history on the back surface is used as the prescribed boundary condition to best match the experimental data, as shown in Fig. 5.

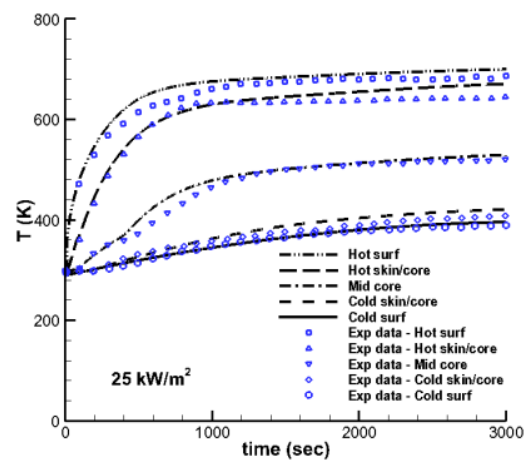

(a)

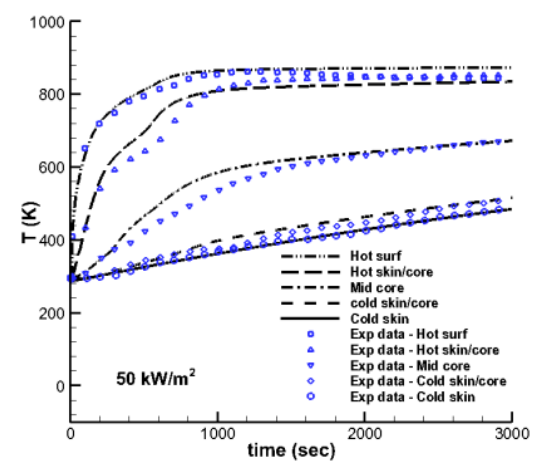

(b)

Fig. 7. Time history of temperature at hot/skin-balsa/balsa middle/balsa-skin/cold surfaces of a sandwich composite panel with locally heating of: (a) $25 \mathrm{~kW} / \mathrm{m}^{2}$; (b) $50 \mathrm{~kW} / \mathrm{m}^{2}$ on left surface. 
Figure 7 shows the time history of temperature at different through-thickness locations in the sandwich composite: exposed surface, skin-balsa interface, balsa middle surface, balsa-skin interface, and unexposed surface. Two different heat fluxes are imposed on the sandwich composite surface, $25 \mathrm{~kW} / \mathrm{m}^{2}$ and $50 \mathrm{~kW} / \mathrm{m}^{2}$, respectively. As shown in Fig. 7, the temperature predictions agree well with experimental data in both cases with a maximum error of $7.2 \%$ and $11.1 \%$, respectively. For the case of $50 \mathrm{~kW} / \mathrm{m}^{2}$, similar to the glass/vinyl ester laminate case in previous section, predicted temperature is slightly higher than the measurements at the skin/balsa interface and middle surface of the balsa. This can be explained by the same reason that the material is decomposed due to a higher temperature distribution but a constant thermal conductivity is assumed for the decomposed material.

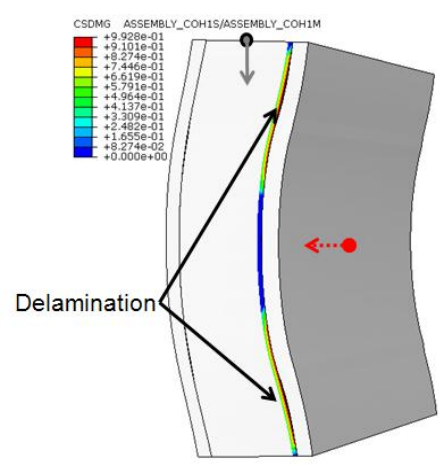

(a)

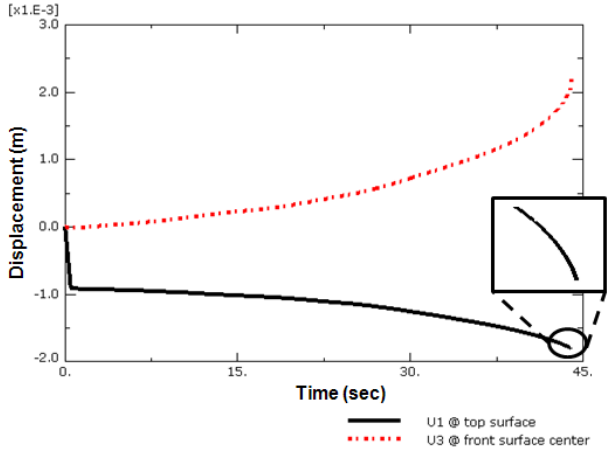

(b)

Fig. 8. (a) Deformed shape and delamination, and (b) history of displacement of composite sandwich under $50 \%$ strength load.

Comparison with experimental data is performed during our mechanical model validation. Efforts have also been focused on predicting the time-to-failure of the composite sandwich under thermal and mechanical loading. It has been observed that the interfaces between composite skin and balsa core delaminated [12] under the thermal-mechanical loading. In order to capture this failure mode, cohesive layers are used to model the skin/core interfaces. The delamination toughness (or, fracture energy) of glass vinyl ester laminate are measured by the Royal Melbourne Institute of Technology (RMIT). A hyperbolic equation is used to curve fit the experimental data. Both Mode I and Mode II are represented as

$$
\begin{aligned}
& G_{I C}=\frac{1060+60}{2}-\frac{1060+60}{2} \tanh [0.035(T-132)] \\
& G_{I C}=\frac{1580+86}{2}-\frac{1580-86}{2} \tanh [0.035(T-131)]
\end{aligned}
$$

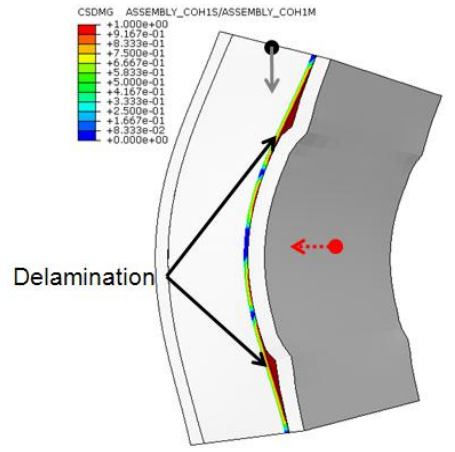

(a)

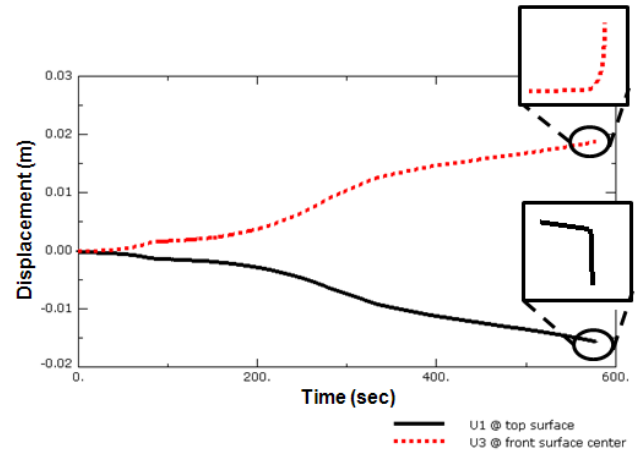

(b)

Fig. 9. (a) Deformed shape and delamination, and (b) history of displacement of composite sandwich under $15 \%$ strength load. 
In the time-to-failure tests the applied heat flux is $50 \mathrm{~kW} / \mathrm{m}^{2}$. A series of compressive loads $(50 \%, 37.5 \%$, $22 \%$ and $15 \%$ of the compressive strength) are applied on the composite sandwich structure. Figures 8 and 9 present the delamination failure and the displacement curves for $50 \%$ and $15 \%$ strength loading cases, respectively. In both cases delamination is predicted between the front skin and balsa core, which is very similar to the failure modes observed experimentally [12], as shown in Fig. 10. The in-plane displacement is found to drop rapidly when the composite sandwich fails. At the same time, the out-of-plane displacement increases quite quickly too (with the positive values being deflection away from the heat source), as shown in Figs. 8b and 9b. In this study, therefore, the time-to-failure is defined as the time when the sudden drop occurs in the in-plane displacement.

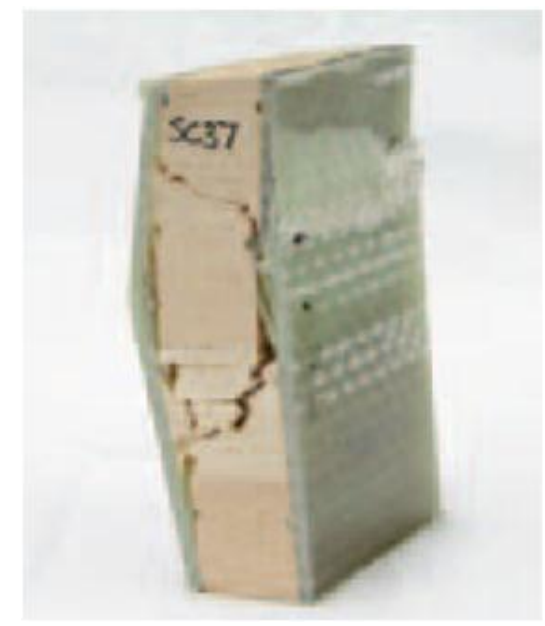

Fig. 10. Failure modes observed in experimental studies by Feih [12].

The in-plane displacement is compared with experimental data [30]. As shown in Fig. 11, the numerical predictions on the in-plane displacement are larger than the measurements especially at lower loading case. However, the time of sudden drop in displacement is comparable to experimental data.

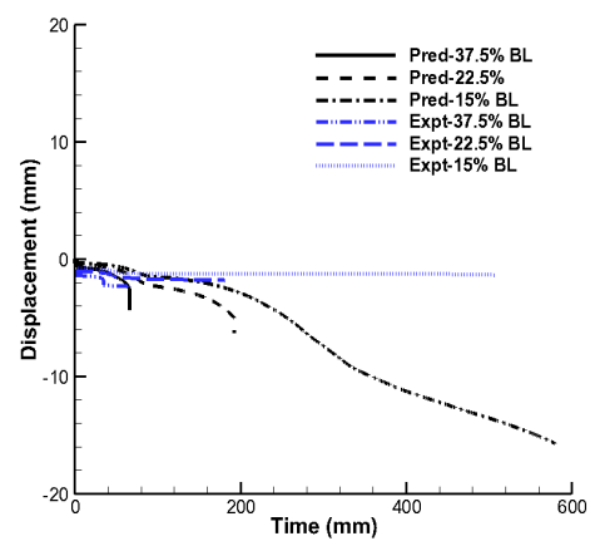

Fig. 11. In-plane displacement of composite sandwich compared with experimental measurements [30]. 


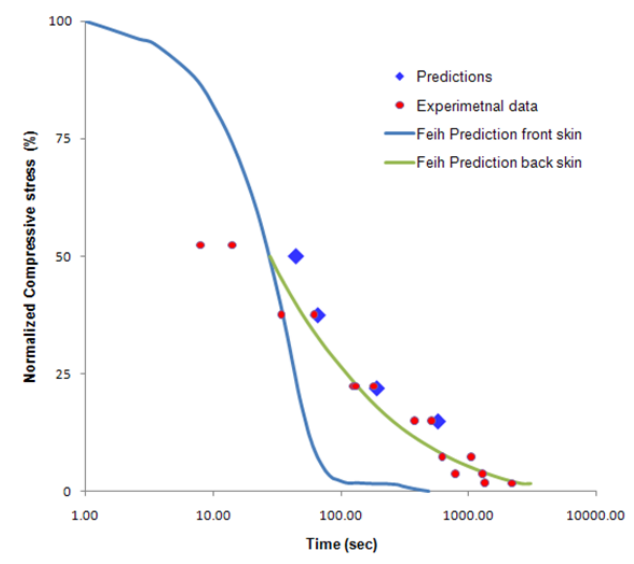

Fig. 12. Time-to-failure prediction under different compressive loadings.

The time-to-failure predictions are compared with experimental data, as shown in Fig. 12. There are two sets of experimental data, for front (not shown) and back skins. According to Feih et al. [12], the failure mode involved collapse of the two skins and shear failure of the core when the applied stress was more than $50 \%$ the strength of the sandwich composite and the front skin failure resulted from the stable plastic kinking. This failure mechanism is not included in the current study. Despite this limitation, the current model predictions of time-to-failure agree reasonably well with experimental failure time based on the back skin failure. The error varies from $6.1 \%$ to $13.7 \%$, compared with the measured back skin failure, for the cases with applied stress less than $50 \%$.

\section{CONCLUSIONS}

This study has focused on the development of a thermal damage model, its extension to a coupled thermodelamination damage model in Abaqus, and their applications to the response prediction of the fiber reinforced polymer composite structures in fire environments. The model is utilized to study the glass/vinyl ester composite laminates and their sandwich structures under thermal and compressive loading. To the authors' knowledge, this is the first study to attempt to simulate the delamination failure of a loaded balsa sandwich panels subject to fire environments. The temperature prediction agrees well with the experimental data. A reasonably good agreement has also been observed between the numerical predictions and experimental data of the time-to-failure for the composite sandwich specimens. Delamination is predicted between the front skin and balsa core where the same failure mode was observed from experiments.

\section{ACKNOWLEDGMENT}

This research has been supported by the Office of Naval Research (ONR) under grant N00014-08-C-0591 with Dr Luise Couchman as the program monitor.

\section{REFERENCES}

[1] Henderson, J.B., Wiebelt, J.A, and Tant, M.R., (1985) A model for the thermal response of polymer composite materials with experimental verification, Journal of Composite Materials, 19:579-595, http://dx.doi.org/10.1177/002199838501900608

[2] Henderson, J.B., and Wiecek, T.E., (1987) A mathematical model to predict the thermal response of decomposing expanding polymer composites, Journal of Composite Materials, 21:373-393, http://dx.doi.org/10.1177/002199838702100406

[3] Florio, J.J., Henderson, J.B., Frederick, L.T., and Hariharan, R.A., (1991) Study of effects of the assumption of local-thermal equilibrium on the overall thermally-induced response of a decomposing glass-filled polymer composite, Journal of Heat and Mass Transfer, 34:135-146, http://dx.doi.org/10.1016/0017-9310(91)90181-D 
[4] Dimitrienko, Y.I., (1997) Thermomechanical behavior of composite materials and structures under high temperatures: 1. materials," Composites Part A, 28:453-461, http://dx.doi.org/10.1016/S1359-835X(96)00144-3

[5] Dimitrienko, Y.I., (1997) Thermomechanical behavior of composite materials and structures under high temperatures: 2. structures, Composites Part A, 28:463-471, http://dx.doi.org/10.1016/S1359-835X(96)00145-5

[6] Dimitrienko, Y.I., (1997) Internal heat-mass transfer and stresses in thin-walled structures of ablating materials, Int. J. Heat Mass Transfer, 40(7):1701-1711, http://dx.doi.org/10.1016/S00179310(96)00149-4

[7] Dimitrienko, Y.I., (1998) Mechanics of porous media with phase transformations and periodical structures 1. method of asymptotic averaging, European Journal of Mechanics -A/Solids, 17(2):305-319, http://dx.doi.org/10.1016/S0997-7538(98)80088-0

[8] Dimitrienko, Y.I., (1998) Mechanics of porous media with phase transformations and periodical structures 2. solutions of local and global problems, European Journal of Mechanics -A/Solids, 17(2):321-337, http://dx.doi.org/10.1016/S0997-7538(98)80089-2

[9] Dimitrienko, Y.I., (2000) Thermomechanical behavior of composites under local intense heating by irradiation, Composites: Part A, 31:591-598, http://dx.doi.org/10.1016/S1359-835X(99)00094$\underline{9}$

[10] Feih. S., Mathys. Z., Gibson. A., and Mouritz. A., "Modeling the tension and compression strengths of polymer laminates in fire," Composites Science and Technology, 2007, 67:551-564, http://dx.doi.org/10.1016/j.compscitech.2006.07.038

[11] Feih, S., Mathys, Z., Gibson, A., and Mouritz, A., (2007) Modeling the compression strengths of polymer laminates in fire, Composites: Part A, 38:2354-2365, http://dx.doi.org/10.1016/j.compositesa.2007.04.013

[12] Feih, S., Mathys, Z., Gibson, A., and Mouritz, A., (2008) Compressive skin failure of sandwich composites in fire, Journal of Sandwich Structures and Materials, 10:217-245, http://dx.doi.org/10.1177/1099636207082307

[13] Summers, P., "Predicting Compression Failure of Fiber-reinforced Polymer Laminates during Fire," M.S. Thesis; Mechanical Engineering, the Virginia Polytechnic Institute and State University, Blacksburg, Virginia, 2010.

[14] Zhang, Z., and Case, S.W., "Finite element modeling for composites exposed to fire," SAMPE 09, Baltimore, MD, 2009, May 18-21.

[15] Zhang, Z., "Thermo-Mechanical Behavior of Polymer Composites Exposed to Fire," Ph.D. Thesis, Engineering Mechanics, the Virginia Polytechnic Institute and State University, Blacksburg, Virginia, 2010.

[16] Luo, C., and DesJardin, P.E., (2007) Thermo-mechanical damage modeling of a glass-phenolic composite materials, Composites Science and Technology, 67:1475-1488, http://dx.doi.org/10.1016/j.compscitech.2006.07.030

[17] Luo, C., "Thermo-mechanical Damage Modeling of a Glass-Phenolic Composite Material," M.S. Thesis, Department of Mechanical and Aerospace Engineering, State University of New York at Buffalo, Buffalo, NY, 2006.

[18] Mouritz, A.P., Feih, S., Kandare, E., Mathys, Z., Gibson, A.G., DesJardin, D.E., Case, S.W., and Lattimer, B.Y. (2009) Review of fire structural modeling of polymer composites, Composites: Part A, 40:1800-1814, http://dx.doi.org/10.1016/j.compositesa.2009.09.001

[19] Luo, C., "Mathematical Modeling of Thermo-Mechanical Damage of Polymer Matrix Composites in Fire," Ph.D. thesis, Department of Mechanical and Aerospace Engineering, State University of New York at Buffalo, Buffalo, NY, 2010.

[20] Abaqus Theory Manual, Simulia/Abaqus, version 6.10 ed., 2010. 
[21] Xu, G., Bower, F., and Ortiz, M., (1994) An analysis of non-planar crack growth under mixed mode loading, International Journal of Solids and Structures, 31:2167-2193, http://dx.doi.org/10.1016/0020-7683(94)90205-4

[22] Abaqus Analysis User's Manual. Simulia/Abaqus, version 6.10 ed., 2010.

[23] Luo, C., Chen, L., Lua, J., Liu, P. "Abaqus fire interface simulator toolkit (AFIST) for coupled fire and structural response prediction," $51^{\text {st }}$ AIAA/ASME/ASCE/AHS/ASC Structures, Structural Dynamics, and Materials Conference, Orlando, FL, AIAA 2010-2768, 2010.

[24] Kim, J., Lee, S.W., and Kwon, S., (2007) Time-to-failure of compressively loaded composite structures exposed to fire, Journal of Composite Materials, 41:2715, http://dx.doi.org/10.1177/0021998307078731

[25] Abaqus User Subroutines Reference Manual. Simulia/Abaqus, version 6.10 ed., 2010.

[26] Lattimer, B.Y., Ouellette, J., Trelles, J., "Thermal response of composite materials to elevated temperature," Modeling of Naval Composite Structures in Fire, Couchman, L., and Mouritz, A., (eds.), 2006.

[27] Case, S.W., Lattimer, B.Y., "Proposed simulations for thermal decomposition model verification," Virginia Tech Extreme Laboratory 2009.

[28] Mouritz, A.P., Feih, S., Mathys, Z., and Gibson, G., "Mechanical property degradation of naval composite materials in fire," Modeling of Naval Composite Structures in Fire, Couchman, L., and Mouritz, A., (eds.), 2006.

[29] Gipple, K. “Out-of-plane composite material property data," NSWCCD-65-TR-1998/16, 1998.

[30] Feih, S., "Experimental measurements on in-plane displacements of sandwich panel," RMIT, Personal Communication, 2010. 